\title{
Avaliação Qualitativa e Quantitativa da Deposição de Calda de PulverizaÇÃo EM Commelina diffusa ${ }^{1}$
}

\author{
Qualitative and Quantitative Evaluation of Spray Deposition of Commelina diffusa
}

RODRIGUES-COSTA, A.C.P. ${ }^{2}$, MARTINS, D. ${ }^{3}$, COSTA, N.V. ${ }^{4}$ e PEREIRA, M.R.R. ${ }^{5}$

\begin{abstract}
RESUMO - Objetivou-se neste trabalho avaliar a quantidade e qualidade da deposição da calda de pulverização em plantas de Commelina diffusa, considerando volumes de aplicação, pontas de pulverização e o ângulo dos bicos na barra de pulverização. Foram utilizadas cinco hastes de plantas por vaso. O delineamento experimental adotado foi o inteiramente casualizado, com 20 repetições. O experimento foi realizado em casa de vegetação, e a aplicação da calda foi efetuada após 40 dias do transplantio das hastes, quando estavam com 30 a $40 \mathrm{~cm}$ de comprimento (em pleno desenvolvimento). Foram avaliadas cinco pontas de pulverização: TX-VK 6 (100 L ha-1), TX-VK 8 (200 L ha $\left.{ }^{-1}\right)$, XR 11001 VS (100 L ha-1), XR 11002 VS (200 L ha-1) e TJ60 $11002 \mathrm{VS}\left(100\right.$ e $\left.200 \mathrm{~L} \mathrm{ha}^{-1}\right)$, as quais foram testadas com diferentes ângulos de aplicação $\left(0^{\circ} \mathrm{e}+30^{\circ}\right)$, exceto a TJ60 11002 VS. Foi utilizado como traçador o corante Azul Brilhante FDC-1 na concentração de 500 ppm, na determinação da deposição da calda de pulverização. Imediatamente após a aplicação, 20 hastes foram coletadas e, em seguida, lavadas em $100 \mathrm{~mL}$ de água destilada, para posterior quantificação do traçador em espectrofotômetro. Os dados foram transformados em valores de depósitos por grama de massa seca e ajustados à curva de regressão pelo modelo de Gompertz. Independentemente da ponta utilizada, o volume de $200 \mathrm{~L} \mathrm{ha}^{-1}$ proporcionou os maiores depósitos nas plantas, destacando-se a ponta TJ60. A ponta XR 11001 VS (100 L ha-1) proporcionou a melhor uniformidade quando se utilizou o ângulo de $+30^{\circ}$.
\end{abstract}

Palavras-chave: volume de aplicação, tecnologia de aplicação, planta daninha.

\begin{abstract}
The objective of this study was to evaluate the quantity and quality of spray deposition in Commelina diffusa plants, considering application volume, spray nozzles and the angle of the bar of the spray nozzles. Five stems of plants/pot were planted. The experimental treatments were set up on a randomized design with twenty replications. The experiment was carried out under greenhouse conditions and the solution was applied after 40 days of stem transplanting, when the plants were between 30 to $40 \mathrm{~cm}$ long (in full development). Five spray nozzles (TX-VK $6(100 \mathrm{~L} \mathrm{ha}-1)$,

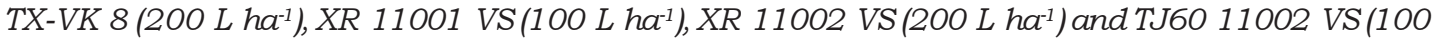

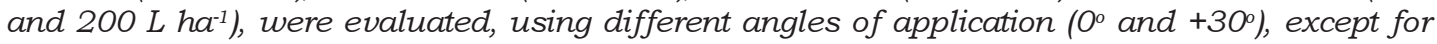
TJ60 11002 VS nozzle. Brilliant blue FDC-1 was used as a tracer solution, with 500 ppm to determine spray deposition. Immediately after application, twenty weed stems were collected, and washed in $100 \mathrm{~mL}$ of distilled water for posterior tracer quantification in a spectrophotometer. The data were adjusted to a regression curve, according to the Gompertz model. Independent of the

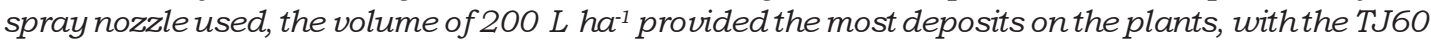
nozzle being the most outstanding. The XR $11001 \mathrm{VS}$ nozzle $\left(100 \mathrm{~L} \mathrm{ha} \mathrm{C}^{-1}\right)$ provided the best uniformity when an angle of $+30^{\circ}$ was used.
\end{abstract}

Keywords: application volume, spraying technology, weed.

Recebido para publicação em 3.8.2010 e na forma revisada em 6.5.2011.

2 Pós-Doutoranda em Agronomia, Universidade Estadual do Oeste do Paraná - UNIOESTE/CCA, Caixa Postal 91, 85960-000 Marechal Cândido Rondon-PR; ${ }^{3}$ Professor Adjunto, Dep. de Produção Vegetal, Faculdade de Ciências Agronômicas, Universidade Estadual Paulista "Júlio de Mesquita Filho" - FCA/UNESP, Fazenda Lageado, Caixa Postal 237, 18603-970 Botucatu-SP; ${ }^{4}$ Professor Adjunto, UNIOESTE/CCA, <neumarciovc@hotmail.com>; ${ }^{5}$ Doutora em Agronomia, Botucatu-SP. 


\section{INTRODUÇÃO}

A espécie Commelina diffusa encontra-se difundida no território brasileiro, podendo causar prejuízos econômicos às culturas agrícolas (Rocha et al., 2007). Em áreas onde há ocorrência dessa espécie e o herbicida glyphosate tem sido utilizado com frequência, a sua população tem aumentado devido à tolerância ao herbicida (Santos et al., 2001).

A dificuldade de controle das diferentes espécies de trapoeraba pode estar associada a fatores referentes à morfoanatomia dessas plantas. Uma vez que a diversidade morfológica da superfície foliar existente entre as espécies de plantas e a presença de estruturas foliares, como tricomas, estômatos, cutícula e ceras, podem exercer grande influência na aderência e deposição das gotas de pulverização, assim como na absorção do herbicida (Hess \& Falk, 1990; Costa et al., 2005).

Apesar de existirem pesquisas que avaliem a eficiência dos herbicidas, há pouca informação sobre a tecnologia de aplicação utilizada. De acordo com Devlin et al. (1991), as dosagens de herbicidas nos rótulos dos produtos estão colocadas muitas vezes em níveis mais altos do que os necessários, de tal modo que o controle das plantas daninhas seja efetivamente garantido em amplas condições de ambiente ou de manejo e, em especial, devido às falhas na tecnologia de aplicação.

A deposição e a uniformidade das aplicações dos produtos fitossanitários estão diretamente relacionadas com as características das plantas, tanto das folhas como da forma das plantas (Holloway, 1970; Barber \& Parkin, 2003), assim como com características da própria pulverização. Por isso, estudos de técnicas de aplicação tornaram-se importantes para melhorar a chegada dos depósitos ao alvo.

O tipo de ponta de pulverização também afeta a deposição das gotas pulverizadas sobre as plantas. Para Galli \& Arruda (1985) e Bauer \& Raetano (2004), a uniformidade de cobertura da pulverização e o tamanho das gotas são fatores que dependem do desempenho do órgão emissor de gotas, que, no caso dos pulverizadores, é a ponta de pulverização - considerada a parte mais importante do equipamento.
A uniformidade da distribuição da calda aplicada em pulverizações de produtos fitossanitários deve-se às condições de operação do equipamento; os fatores responsáveis por uma boa aplicação são: espaçamento entre bicos, pressão de trabalho, altura da barra e ângulo de abertura dos bicos (Perecin et al., 1994). O volume aplicado numa pulverização deve ser o mais uniforme possivel, sob pena de ser necessário um volume adicional para compensar os pontos ou faixas que receberam menor quantidade de calda (Perecin et al., 1998).

Têm-se observado em campo inúmeras falhas no controle químico da trapoeraba, as quais podem estar relacionadas a falhas na aplicação dos produtos. A calda pulverizada pode não estar atingindo as plantas de forma adequada, com boa deposição das gotas sobre suas folhas. Assim, objetivou-se neste estudo avaliar a quantidade e qualidade da deposição da calda de pulverização em plantas de C. diffusa, considerando volumes de aplicação, pontas de pulverização e o ângulo dos bicos na barra de pulverização.

\section{MATERIAL E MÉTODOS}

O estudo foi realizado em condições de casa de vegetação, no Núcleo de Pesquisas Avançadas em Matologia (NUPAM), pertencente ao Departamento de Produção Vegetal FCA/UNESP, campus de Botucatu-SP.

As plantas de $C$. diffusa foram cultivadas em vasos com capacidade de cinco litros, contendo solo classificado, de acordo com Embrapa (1999), como Latossolo Vermelho-Escuro, textura média, com as seguintes características: $\mathrm{pH}\left(\mathrm{CaCl}_{2}\right)=4,1$; matéria orgânica $\left(\mathrm{g} \mathrm{dm}^{-3}\right)=$ 18,$0 ; \mathrm{P}\left(\mathrm{mg} \mathrm{dm}^{-3}\right)=8,0 ; \mathrm{H}+\mathrm{Al}, \mathrm{K}, \mathrm{Ca}, \mathrm{Mg}, \mathrm{SB}$ e CTC $\left(\mathrm{mmol}_{c} \mathrm{dm}^{-3}\right)=67,0 ; 0,1 ; 1,0 ; 1,0 ; 2,0 ;$ e 68,0; respectivamente; e V\% $=3,0$. Para cada vaso, realizou-se a calagem do solo, aplicandose $15 \mathrm{~g}$ de calcário dolomítico para atingir o V\% igual a 70 e adubação com $3 \mathrm{~g}$ da fórmula 4-14-8 de NPK incorporado ao solo antes do transplantio das estacas.

Os exemplares das plantas de C. diffusa utilizados para retirada das estacas foram coletados em áreas agrícolas do município de Ponta Grossa-PR. Utilizaram-se estacas de trapoeraba com aproximadamente $15 \mathrm{~cm}$ de 
comprimento, com 2-3 folhas, colocando-se cinco hastes por vaso. Os tratamentos consistiram de pontas de pulverização: (i) pontas TX-VK 6 (100 $\left.\mathrm{L} \mathrm{ha}^{-1}\right)$ e TX-VK 8 (200 L ha ${ }^{-1}$ ) de jato cônico vazio, com formação de gotas pequenas e com ângulo de abertura do jato de $80^{\circ}$; (ii) pontas XR 11001 VS (100 L ha ${ }^{-1}$ ) e XR 11002 VS (200 L ha-1) de jato plano, com espectro de gotas grandes ou pequenas, dependendo da pressão utilizada, e com ângulo de abertura de $110^{\circ}$; e (iii) ponta de jato plano duplo TJ60 11002 VS (100 e $200 \mathrm{~L} \mathrm{ha}^{-1}$ ), com formação de gotas menores para cobertura completa e ângulo de abertura de $110^{\circ}$. As pontas de jato cônico vazio e jato plano foram avaliadas quanto ao ângulo de aplicação $\left(0^{\circ} \mathbf{e}+30^{\circ}\right)$. Para a ponta TJ60 11002 VS, foi modificada a pressão de aplicação para se obter o volume desejado de 100 e $200 \mathrm{~L} \mathrm{ha}^{-1}$. Ressalta-se que todas as pontas de pulverização utilizadas no ensaio eram novas; aferiu-se a pressão de trabalho e vazão antes de cada aplicação, de acordo com as especificações do fabricante.

Os tratamentos foram dispostos no delineamento inteiramente casualizado com quatro repetições. Para as análises quantitativa e qualitativa dos depósitos, cada haste foi considerada uma repetição, totalizando 20 repetições por tratamento. A aplicação da calda foi realizada 40 dias após o transplantio, quando as hastes das plantas encontravamse com 30 a $40 \mathrm{~cm}$ de comprimento (em pleno desenvolvimento).

A calda de pulverização foi preparada adicionando-se 0,5 g de corante Azul Brilhante (FDC-1) por litro de água destilada, o que equivale à concentração de 500 ppm, para determinação da deposição da calda de pulverização. Segundo Palladini (2005), esse corante não influi nas características físicas da calda, podendo ser utilizado como traçador para simulação de aplicações de herbicidas.

A aplicação foi realizada com auxílio de um pulverizador estacionário pressurizado a ar comprimido com pressão constante, em sala fechada, equipado com barra de pulverização posicionada a $0,5 \mathrm{~m}$ de altura das plantas e munida de quatro pontas de pulverização, com espaçamento de 0,5 m entre bicos. Durante a aplicação, a temperatura e umidade relativa do ar variaram de 24,4 a $28,6{ }^{\circ} \mathrm{C}$ e de 49 a $53 \%$, respectivamente.

Imediatamente após a aplicação da calda de pulverização, procedeu-se à coleta individual de todas as hastes da espécie em estudo; em seguida, elas foram levadas ao laboratório para serem lavadas em $100 \mathrm{~mL}$ de água destilada. Posteriormente, fez-se a quantificação do traçador em cada amostra por meio de espectrofotometria, conforme metodologia descrita por Souza et al. (2007).

Após a lavagem, as hastes foram colocadas em sacos de papel etiquetados e levadas a uma estufa de ventilação forçada de ar a temperatura de $60 \pm 2{ }^{\circ} \mathrm{C}$ por 72 horas, até atingirem massa constante. Em seguida, as hastes foram retiradas e pesadas, para determinação da massa seca.

Os dados, em porcentagem, obtidos dos depósitos foram ajustados pelo modelo de Gompertz $F=e^{\left[a-e^{(-b-c x)}\right]}$, para representar a frequência acumulada $(\mathrm{F})$ da deposição da calda pulverizada, conforme metodologia descrita por Souza et al. (2007).

Com o mesmo modelo, foram calculados os valores de média, moda, mediana e os percentis $1,0,5,0$ e $10,0 \%$. Os percentis foram calculados igualando-se a expressão de frequência acumulada a cada um desses valores, estimando a quantidade que recebe essa proporção de menor deposição da população de plantas avaliadas. A precisão do ajuste dos dados do modelo de Gompertz foi avaliada por meio dos coeficientes de determinação $\left(R^{2}\right)$ e pela soma dos quadrados dos resíduos das equações, utilizando-se o programa estatístico Sigmastat 2.0.

As médias de deposição $\left(\mathrm{mL} \mathrm{g}^{-1}\right.$ de massa seca) encontradas também foram submetidas à análise de variância pelo teste $\mathrm{F}$ e comparadas pelo teste de Tukey a $5 \%$ de probabilidade. A análise de variância e comparação de médias foi feita pelo programa SISVAR.

\section{RESULTADOS E DISCUSSÃO}

Na Tabela 1 estão apresentados os valores médios dos depósitos que alcançaram as plantas de C. diffusa. Observa-se que as pontas 
Tabela 1 - Volume médio de calda depositada em plantas de Commelina diffusa. Botucatu-SP, 2006/07

\begin{tabular}{|c|c|c|}
\hline Ponta de pulverização & $\begin{array}{l}\text { Ângulo de } \\
\text { aplicação }\end{array}$ & $\begin{array}{l}\text { Deposição } \\
\left(\mu \mathrm{L} \mathrm{g}^{-1} \mathrm{de}\right. \\
\text { massa seca) }\end{array}$ \\
\hline TX-VK $6\left(100 \mathrm{~L} \mathrm{ha}^{-1}\right)$ & $0^{\circ}$ & $125,08 \mathrm{~cd}$ \\
\hline TX-VK $6\left(100 \mathrm{~L} \mathrm{ha}^{-1}\right)$ & $+30^{\circ}$ & $116,88 \mathrm{~cd}$ \\
\hline TX-VK $8\left(200 \mathrm{~L} \mathrm{ha}^{-1}\right)$ & $0^{\circ}$ & $215,03 \mathrm{ab}$ \\
\hline TX-VK $8\left(200 \mathrm{~L} \mathrm{ha}^{-1}\right)$ & $+30^{\circ}$ & $275,50 \mathrm{a}$ \\
\hline XR 11001 VS $\left(100 \mathrm{~L} \mathrm{ha}^{-1}\right)$ & $0^{\circ}$ & $115,38 \mathrm{~cd}$ \\
\hline XR $11001 \mathrm{VS}\left(100 \mathrm{~L} \mathrm{ha}^{-1}\right)$ & $+30^{\circ}$ & $94,64 \mathrm{~d}$ \\
\hline XR 11002 VS $\left(200 \mathrm{~L} \mathrm{ha}^{-1}\right)$ & $0^{\circ}$ & $176,28 \mathrm{bc}$ \\
\hline XR 11002 VS $\left(200 \mathrm{~L} \mathrm{ha}^{-1}\right)$ & $+30^{\circ}$ & $268,75 \mathrm{a}$ \\
\hline TJ $6011002 \mathrm{VS}\left(100 \mathrm{~L} \mathrm{ha}^{-1}\right)$ & -- & $188,19 \mathrm{bc}$ \\
\hline TJ 6011002 VS $\left(200 \mathrm{~L} \mathrm{ha}^{-1}\right)$ & -- & $210,62 \mathrm{ab}$ \\
\hline $\mathrm{F}_{\text {tratamento }}$ & \multicolumn{2}{|c|}{14,84} \\
\hline d.m.s. & \multicolumn{2}{|c|}{76,07} \\
\hline $\mathrm{CV}(\%)$ & \multicolumn{2}{|c|}{42,1} \\
\hline
\end{tabular}

Médias seguidas de mesma letra minúscula, na coluna, não diferem estatisticamente entre si pelo teste de Tukey $(p>0,05)$ Significativo a $1 \%$ de probabilidade.

TX-VK 8 e XR 11002 VS, com volume de $200 \mathrm{~L} \mathrm{ha}^{-1}$ e angulação de $+30^{\circ}$, foram os tratamentos que conferiram os maiores depósitos médios de calda pulverizada. Nota-se que, para o maior volume, o efeito da angulação proporcionou incrementos nos depósitos médios das plantas da ordem de 28,12 e $50,76 \%$ para as pontas TX-VK 8 e XR 11002 VS, respectivamente.

Silva (2000) estudou os depósitos de calda de pulverização no solo e em plantas de tiririca em diferentes condições de aplicação, concluindo que, entre as variáveis estudadas (tipos de ponta, ângulo de inclinação das pontas, densidade da planta daninha e velocidade de aplicação), o ângulo de inclinação e a densidade populacional foram os que influenciaram de forma mais intensa a deposição da solução de pulverização e do traçante utilizado. Esse pesquisador observou ainda que os maiores valores de depósitos nas plantas foram proporcionados pelos ângulos de $+15^{\circ} \mathrm{e}+30^{\circ}$, uma vez que esses depósitos foram 26,3 e $50,6 \%$ superiores aos proporcionados pelo ângulo de $0^{\circ}$, corroborando os resultados ora encontrados para essas duas pontas.
Ressalta-se que o menor valor de depósitos médios verificado nas plantas de $C$. diffusa foi proporcionado pela ponta XR 11001 VS (100 L ha ${ }^{-1}$ ) e angulação de $+30^{\circ}$; nesse caso, os resultados não corroboram os de vários pesquisadores, como Silva (2000), Martins (2004) e Tomazela et al. (2006), que trabalharam com tiririca, batata e capim-marmelada, respectivamente.

Na Tabela 2 são apresentados os valores correspondentes aos parâmetros calculados a partir do ajuste da regressão por meio do modelo de Gompertz para a frequência acumulada e os depósitos, em relação ao modelo de ponta de pulverização, volume e ângulo de aplicação das plantas de $C$. diffusa. Os coeficientes de determinação foram elevados $\left(R^{2}\right.$ entre 0,96 e 0,99) para todas as pontas de pulverização, volumes e ângulos de aplicação. Também são apresentados os valores de média, mediana, moda e coeficiente de variação.

O modelo de ponta XR 11002 VS seguido pela ponta TX-VK 8, ambas com volumes de $200 \mathrm{~L} \mathrm{ha}^{-1}$ e angulação de $+30^{\circ}$, foram os tratamentos que apresentaram os maiores valores de moda (Tabela 2), indicando os maiores valores frequentes de depósitos pontuais que ocorreram nas plantas de C. diffusa. Os menores depósitos pontuais encontrados foram conferidos pelos tratamentos com as pontas TX-VK 6 e XR 10001 VS, no volume de $100 \mathrm{~L} \mathrm{ha}^{-1}$ e com ângulo de $+30^{\circ}$.

Quando se utilizou o ângulo de $+30^{\circ}$, houve acréscimo nos depósitos pontuais em todos os tratamentos com volume de $200 \mathrm{~L} \mathrm{ha}^{-1}$; contudo, esses depósitos pontuais decresceram no menor volume de aplicação, com exceção da ponta XR 11002 VS.

Rodrigues et al. (2010) observaram, em plantas de $C$. benghalensis, que com a utilização do ângulo de $+30^{\circ} \mathrm{em}$ pontas de pulverização houve incremento nos depósitos pontuais para o volume de $100 \mathrm{~L} \mathrm{ha}^{-1}$, enquanto houve redução quando se utilizou o volume de $200 \mathrm{~L} \mathrm{ha}^{-1}$. Esses autores explicam que, provavelmente, a maior angulação pode ter favorecido a ocorrência de deriva, uma vez que pulverizações com maior volume de aplicação favorecem a formação de gotas com diâmetros reduzidos. No entanto, ressalta-se que as diferenças morfológicas e anatômicas entre 
Tabela 2 - Resultados das análises de regressão das frequências acumuladas e valores de médias, mediana, moda e coeficiente de variação dos depósitos do traçador, em $\mu \mathrm{L} \mathrm{g}^{-1}$ de massa seca, em plantas de Commelina diffusa. Botucatu-SP, 2006/07

\begin{tabular}{|c|c|c|c|c|c|c|c|c|c|c|c|}
\hline \multirow{5}{*}{\multicolumn{2}{|c|}{$\begin{array}{c}\text { Modelo } \\
\mathrm{y}=\mathrm{e}^{\left[\mathrm{a}-\mathrm{e}^{(-\mathrm{b}-\mathrm{cx})}\right]}\end{array}$}} & \multicolumn{2}{|c|}{ TX-VK 6} & \multicolumn{2}{|c|}{ TX-VK 8} & \multicolumn{2}{|c|}{ XR $11001 \mathrm{VS}$} & \multicolumn{2}{|c|}{ XR 11002 VS } & \multicolumn{2}{|c|}{ TJ60 11002 VS } \\
\hline & & \multicolumn{10}{|c|}{ Ângulo } \\
\hline & & $0^{\circ}$ & $+30^{\circ}$ & $0^{\circ}$ & $+30^{\circ}$ & $0^{\circ}$ & $+30^{\circ}$ & $0^{\circ}$ & $+30^{\circ}$ & -- & -- \\
\hline & & \multicolumn{10}{|c|}{ Volume $\left(\mathrm{L} \mathrm{ha}^{-1}\right)$} \\
\hline & & 100 & 100 & 200 & 200 & 100 & 100 & 200 & 200 & 100 & 200 \\
\hline \multirow{3}{*}{$\begin{array}{l}\text { Estimativa dos } \\
\text { Parâmetros }\end{array}$} & $\mathrm{a}$ & 4,605 & 4,605 & 4,605 & 4,605 & 4,605 & 4,605 & 4,605 & 4,605 & 4,605 & 4,610 \\
\hline & $\mathrm{b}$ & $-2,546$ & $-2,324$ & $-2,299$ & $-4,079$ & $-1,860$ & $-2,774$ & $-2,564$ & $-2,813$ & $-2,602$ & $-2,670$ \\
\hline & $\mathrm{c}$ & 0,028 & 0,029 & 0,012 & 0,020 & 0,019 & 0,036 & 0,017 & 0,013 & 0,016 & 0,020 \\
\hline \multicolumn{2}{|l|}{ SQRegressão } & $16.268,41$ & $18.305,52$ & $15.838,19$ & $17.411,83$ & $17.049,19$ & $16.458,51$ & $16.880,95$ & $15.958,51$ & $16.741,18$ & $17.187,62$ \\
\hline \multicolumn{2}{|l|}{ SQResíduo } & 213,42 & 238,69 & 785,53 & 342,42 & 186,19 & 342,93 & 147,45 & 600,78 & 247,948 & 163,077 \\
\hline \multicolumn{2}{|l|}{ SQTotal } & $16.481,83$ & $18.544,21$ & $16.623,71$ & $17.754,26$ & $17.235,38$ & $16.801,43$ & $17.028,40$ & $16.559,29$ & $16.989,13$ & $17.350,69$ \\
\hline \multicolumn{2}{|l|}{ FRegressão } & 406,54 & 409,02 & 107,53 & 271,19 & 488,37 & 255,97 & 610,59 & 141,67 & 360,10 & 562,11 \\
\hline \multicolumn{2}{|l|}{$\mathrm{R}^{2}$} & 0,99 & 0,99 & 0,95 & 0,98 & 0,99 & 0,98 & 0,99 & 0,96 & 0,99 & 0,99 \\
\hline \multicolumn{2}{|l|}{ Média } & 125,08 & 116,88 & 215,03 & 275,50 & 115,38 & 94,64 & 176,28 & 268,75 & 188,19 & 210,62 \\
\hline \multicolumn{2}{|l|}{ Mediana } & 104,02 & 92,14 & 216,71 & 222,28 & 116,57 & 86,28 & 172,38 & 254,36 & 189,08 & 193,15 \\
\hline \multicolumn{2}{|l|}{ Moda } & 90,93 & 79,59 & 186,91 & 203,95 & 97,38 & 76,21 & 150,82 & 225,04 & 165,73 & 169,81 \\
\hline \multicolumn{2}{|l|}{ CV $(\%)$} & 4,85 & 5,03 & 3,22 & 4,34 & 2,85 & 5,28 & 4,11 & 2,70 & 3,08 & 2,42 \\
\hline
\end{tabular}

$\mathrm{X}=$ porcentagem de depósito do traçador em relação ao total aplicado; a, b e c são estimativas dos parâmetros do modelo para o traçador. - significativo a $1 \%$ de probabilidade.

C. diffusa e C. benghalensis podem ter influenciado na capacidade de retenção das gotas de pulverização (Rocha et al., 2000, 2007).

A qualidade da deposição pode ser analisada por meio das Figuras 1 e 2, nas quais estão apresentadas as deposições avaliadas pelo modelo de Gompertz. A partir da frequência acumulada dada pelo modelo, foi construída a Figura 1, em que a menor inclinação da curva corresponde ao maior valor do parâmetro "c" do modelo (Tabela 2) e indica a menor dispersão dos depósitos da calda $\mathrm{g}^{-1} \mathrm{de}$ massa seca. Isso também pode ser visualizado por meio das frequências não acumuladas (Figura 2), onde as curvas mais afuniladas correspondem à menor curtose dos dados e mostram a frequência de valores extremos, pois, quanto mais plano for o pico, maior será a curtose e pior será a homogeneidade dos depósitos.

Nesta avaliação, os tratamentos que produziram os depósitos de calda mais uniformes foram os correspondentes às pontas XR 11001 VS e TX-VK 6 com volume de $100 \mathrm{~L} \mathrm{ha}^{-1}$ e ângulo de aplicação de $+30^{\circ}$. No entanto, as pontas que apresentaram depósitos de maior variação de uniformidade foram XR 11002 VS
(200 L ha ${ }^{-1}$ ) com ângulo de aplicação de $+30^{\circ} \mathrm{e}$ TX-VK 8 (200 L ha ${ }^{-1}$ ) com ângulo de aplicação de $0^{\circ}$. As menores variações de uniformidade de deposição foram obtidas para os menores volumes de calda, independentemente das pontas avaliadas.

Em C. benghalensis, Rodrigues et al. (2010) verificaram maior desuniformidade nos depósitos de calda de pulverização quando se utilizou a angulação $+30^{\circ}$ no volume de $100 \mathrm{~L} \mathrm{ha}^{-1}$, em relação ao volume de $200 \mathrm{~L} \mathrm{ha}^{-1}$. Pode-se observar que, para garantir a qualidade da deposição de gotas no alvo, deve-se considerar a espécie presente na área, de maneira a se utilizar a técnica mais adequada na deposição de gotas de pulverização.

Os percentis $(1,0,5,0$ e $10,0 \%)$ da população de plantas em que menos ocorreram depósitos da calda de pulverização podem ser responsáveis pelo insucesso da aplicação de produtos fitossanitários (Negrisoli et al., 2002). Assim, em 1,0 e 5,0\% das plantas que menos receberam depósitos, as pontas TX-VK 6 e XR $11001 \mathrm{VS}$ no volume de $100 \mathrm{~L} \mathrm{ha}^{-1}$ e nos dois ângulos testados proporcionaram os menores depósitos. Entretanto, ao observar os $10,0 \%$ da população que recebem menos 
depósitos, os tratamentos mais comprometidos foram os que proporcionaram volumes baixos nos dois ângulos testados: $0^{\circ} \mathrm{e}+30^{\circ}$ (Tabela 3 ).
As pontas XR 11002 VS e TX-VK 8 apresentaram os maiores depósitos em 1,0\% da população que menos recebeu deposição, com

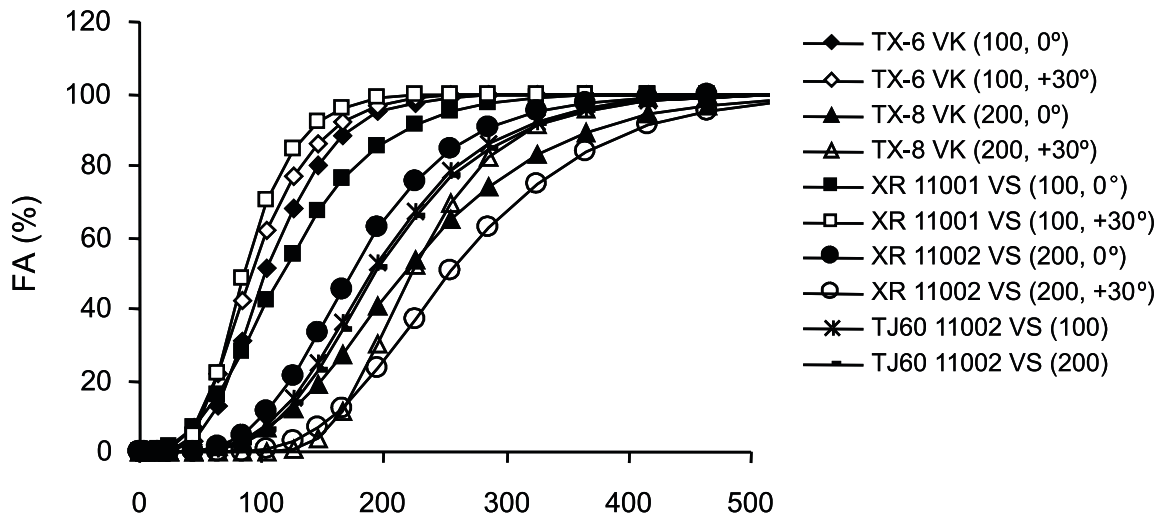

$\mu \mathrm{L} \mathrm{g}{ }^{-1}$

Figura 1 - Frequência acumulada (FA \%) em função da deposição do traçador em plantas de Commelina diffusa, para diferentes pontas de pulverização. Botucatu-SP, 2006/07.

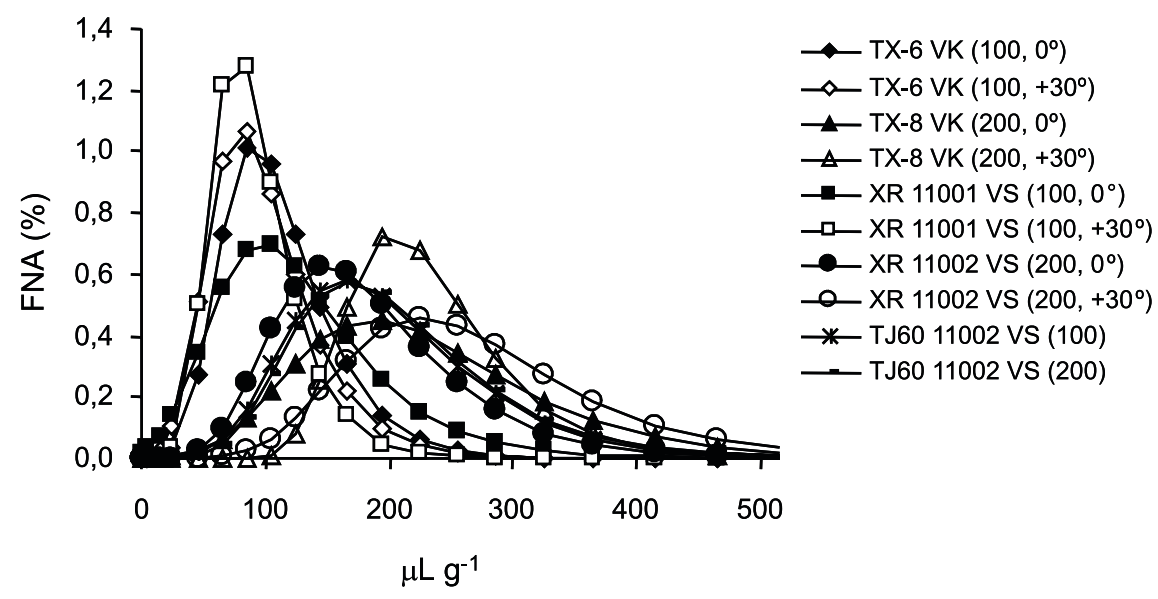

Figura 2 - Frequência não acumulada (FNA \%) em função da deposição do traçador em plantas de Commelina diffusa, para diferentes pontas de pulverização. Botucatu-SP, 2006/07.

Tabela 3 - Deposição da calda de pulverização, em $\mu \mathrm{L} \mathrm{g}^{-1}$ de massa seca, nas populações de Commelina diffusa em que menos ocorreram depósitos. Botucatu-SP, 2006/07

\begin{tabular}{|c|c|c|c|c|c|c|c|c|c|c|}
\hline \multirow{5}{*}{$\begin{array}{l}\text { Porcentagem } \\
\text { (\%) }\end{array}$} & \multicolumn{2}{|c|}{ TX-VK 6} & \multicolumn{2}{|c|}{ TX-VK 8} & \multicolumn{2}{|c|}{ XR 11001 VS } & \multicolumn{2}{|c|}{ XR 11002 VS } & \multicolumn{2}{|c|}{ TJ60 11002 VS } \\
\hline & \multicolumn{10}{|c|}{ Ângulo } \\
\hline & $0^{\circ}$ & $+30^{\circ}$ & $0^{\circ}$ & $+30^{\circ}$ & $0^{\circ}$ & $+30^{\circ}$ & $0^{\circ}$ & $+30^{\circ}$ & -- & -- \\
\hline & \multicolumn{10}{|c|}{ Volume $\left(\mathrm{L} \mathrm{ha}^{-1}\right)$} \\
\hline & 100 & 100 & 200 & 200 & 100 & 100 & 200 & 200 & 100 & 200 \\
\hline 1 & 36,39 & 27,29 & 62,75 & 127,59 & 17,43 & 34,25 & 60,99 & 102,87 & 68,46 & 72,54 \\
\hline 5 & 51,74 & 42,01 & 97,71 & 149,09 & 39,94 & 46,07 & 86,28 & 137,26 & 95,85 & 99,92 \\
\hline 10 & 61,14 & 51,03 & 119,10 & 162,25 & 53,72 & 53,30 & 101,76 & 158,32 & 112,61 & 116,69 \\
\hline
\end{tabular}


valores de 102,87 e 127,59 $\mu \mathrm{L} \mathrm{g}^{-1}$ massa seca, respectivamente, quando se utilizou o ângulo de $+30^{\circ}$. Esse resultado pode indicar que o uso dessas pontas em condições de campo evita a ocorrência de escapes de controle de $C$. diffusa, porém mais estudos devem ser realizados.

Esses resultados demonstraram que, de modo geral, maiores volumes proporcionaram maiores depósitos médios e pontuais de calda de pulverização, independentemente da ponta utilizada, e que a angulação $\left(+30^{\circ}\right.$ ) das pontas de pulverização pode incrementar depósitos de calda e a uniformidade de deposição, mas são dependentes da ponta de pulverização.

\section{LITERATURA CITADA}

BARBER, J. A. S.; PARKIN, C. S. Fluorescent tracer technique for measuring the quantity of pesticide deposited to soil following spray applications. Crop Protec., v. 22, n. 1, p. $15-21,2003$

BAUER, F. C.; RAETANO, C. G. Distribuição volumétrica de calda produzida pelas pontas pulverização XR, TP e TJ sob diferentes condições operacionais. Planta Daninha, v. 22 , n. 2 , p. $275-284,2004$

COSTA, N. V. et al. pH foliar e deposição de gotas de pulverização em plantas daninhas aquáticas: Brachiaria mutica, Brachiaria subquadripara e Panicum repens. Planta Daninha, v. 23, n. 2, p. 295-304, 2005.

DEVLIN, D. L.; LONG, J. H.; MADDLUX, L. D. Using reduced rates of postemergence herbicides in soybean (Glycine max). Weed Technol., v. 5, n. 4, p. 834-40, 1991.

EMPRESA BRASILEIRA DE PESQUISA AGROPECUÁRIA - EMBRAPA. Centro nacional de pesquisa de solos. Sistema brasileiro de classificação de solos. Brasília: Embrapa Produção de Informação/Rio de Janeiro: Embrapa Solos, 1999. 412 p.

GALLI, J. C.; ARRUDA, A. C. Distribuição volumétrica dos bicos pulverizadores JD14-2. Pesq. Agropec. Bras., v. 20, n. 11, p. $1239-1244,1985$.

HESS, F. D.; FALK, R. H. Herbicide deposition on leaf surfaces. Weed Science. v.38, n. 3, p.280-288, 1990.

HOLLOWAY, P. J. Surface factors affecting the wetting of leaves. Pestic. Sci., v. 1, n. 1, p. 56-63, 1970.
MARTINS, D. Deposição de calda de pulverização em cultivares de batata. 2004. 249 f. Tese (Livre Docência em Agricultura/Produção Vegetal) - Universidade Estadual Paulista, Botucatu, 2004.

NEGRISOLI, E. et al. Depósitos unitários de calda de pulverização com e sem surfactante em plantas de Salvinia molesta. Planta Daninha, v. 20, p. 51-56, 2002. (Edição Especial)

PALLADINI, L. A.; RAETANO, C. G., VELINI, E. D. Choice of tracers for the evaluation of spray deposits. Sci. Agric., v. 62, n. 5, p. 440-445, 2005.

PERECIN, D. et al. Padrões de distribuição obtidos com bico Twinjet, em função da altura e do espaçamento entre bicos.

Eng. Agric., v. 14, n. 1, p. 19-30, 1994.

PERECIN, D. et al. Padrões de distribuição obtidos com bicos TF-4, TJ60-11006 e TQ15006 em mesa de prova. Pesq. Agropec. Bras., v. 33, n. 1, p. 175-82, 1998.

ROCHA, D. C.; RODELLA, R. A.; MARTINS, D. Ocorrência de Commelina villosa como planta daninha em áreas agrícolas no Estado do Paraná-PR, Brasil.

Planta Daninha, v. 18, n. 1, p. 161-167, 2000.

ROCHA, D. C.; RODELLA, R. A.; MARTINS, D. Caracterização morfológica de espécies de trapoeraba (Commelina spp.) utilizando a análise multivariada. Planta Daninha, v. 25, n. 4, p. 671-678, 2007.

RODRIGUES, A. C. P. et al. Avaliação qualitativa e quantitativa na deposição de calda de pulverização em Commelina benghalensis. Planta Daninha, v. 28, n. 2, p.421-428, 2010.

SANTOS, I. C. et al. Germinação de sementes aéreas e subterrâneas de Commelina benghalensis. Planta Daninha, v. 19, n. 2, p.163-170, 2001.

SILVA, M. A. S. Depósitos da calda de pulverização no solo e em plantas de tiririca (Cyperus rotundus $\mathrm{L}$.) em diferentes condições de aplicação. 2000. 57 f. Tese (Doutorado em Agronomia/Agricultura) - Universidade Estadual Paulista, Botucatu, 2000

SOUZA, R. T.; VELINI, E. D.; PALLADINI, L. A. Aspectos metodológicos para análise de depósitos de pulverizações pela determinação dos depósitos pontuais. Planta Daninha, v. 25 , n. 1, p. $195-202,2007$

TOMAZELA, M. S. et al. Avaliação da deposição da calda de pulverização em função da densidade populacional de Brachiaria plantaginea, do volume e do ângulo de aplicação. Planta Daninha, v. 24, n. 1, p. 183-189, 2006. 